\title{
Reading between the lines: Identifying communication of deception in social media
}

\author{
Aifuwa Edosomwan \\ School of Media and Communication, Pan-Atlantic University
}

\begin{abstract}
Understanding verbal and nonverbal communication is critical to maintenance of interpersonal relationships. The world has become a global village that allows room for direct access to people and information from around the world through the use of social media networks and its technologies. Not all individuals taking advantage of this network may do so for innocent intentions or for the right reasons and this is why it is important to understand the motivations behind the practice of deception in social media as well as cues to identify it towards protection against deceptive advances. This work seeks to discuss the issues surrounding this problem and elaborates on the different ways to detect deception whether through verbal or nonverbal communicative means. The paper however highlights the reasons why deception is practiced and how nonverbal communication elements can be an effective means of identifying deception communication and the measures to take to manage the threat on social media communities and networks.
\end{abstract}

Keywords: deceiver; receiver; nonverbal communication, cues, social media 


\section{International Academic Conference on Research in SOCIAL SCIENCES}

\section{Introduction}

Since the proliferation of social media, communication channels have shifted from traditional to social media. It has created a boom in the industry and has largely closed some of the preexisting communication gaps but has however given room for new and even more prevalent and seemingly uncontrollable opportunities for deception in communication.

Over the years, solutions have been proposed towards developing means of detecting deception in social and online media use. These solutions have primarily focused on verbal communication in detecting deception (e.g CAPTCHA computation, text and speech). However, this work posits that non-verbal communication (user activity, movement and history) whose cues are four times more powerful than verbal cues can be explored and implemented as an alternative and possibly even more effective means of detecting and preventing deception (Tsikerdekis \& Zeadally, 2014).

From a communication perspective, this work discusses deception and the communication of it through verbal and non-verbal means as well as cues to detect deception or deception tactics. The work expands on the communication theories that further enrich our understanding of the deception process as well as explains the strategies deployed by the deceiver and cues to detect lie-telling especially on social media platforms.

\section{Verbal and Non-verbal Communication}

Verbal and nonverbal communication can influence social interactions and reaction to those interactions (Capella \& Greene, 1982). This therefore, highlights the importance of managing impressions to affect and favorably influence resulting outcomes (Riggio \& Friedman, 1986). Social interactions and cues manifest in verbal responses as well as nonverbal responses (body language, facial expression and other complex behavioral responses. Hence accurate interpretation of these verbal and non-verbal communication cues is a necessary skill to develop in order to deduce perceptions and understanding (McFall, 1982).

Verbal communication messaging may entail cognitive effort and is likely to be more apparent to decode than nonverbal communication signs. However, Fichten, Tagalakis, Judd, Wright and Amsel (2001) reveal that nonverbal communication messaging tend to reflect a more authentic and genuine nature of communication messaging especially with regard to deception detection (Ekman \& O’Sullivan, 1991; DePaulo, Stone \& Lassiter, 1985; Stiff \&Miller 1986). 


\section{International Academic Conference on Research in SOCIAL SCIENCES}

\section{Communication in Social Media}

Social media communication in recent times has been understood to evolve from other traditional communication. For instance, according to Pérez-Sabater (2012) email and LinkedIn communication has taken on a more formal approach as an alternative to formal /mailed letters or as a variation of the practice while on the other hand, communication on Facebook, Twitter and Instagram that have manifested less-structural features such as opening and closings. The difference in audience is believed to be responsible for the variations in tone of communication between these ranges of social media communication platforms.

Email correspondence on social media is often targeted. This means that the likelihood exists that the email communication is usually directed towards the intended recipient with the knowledge that only the party intended will be privy to this message provided that the recipient does not choose to share the content of the message with other parties. Contemporary communication, however, on social network oriented channels is used with the understanding that there is a higher probability that there may be multiple observers of the message intended for the recipient.

Aside from text interactions which constitute verbal communication, online social media provides access to video technology as well as emoticons which can be understood to constitute nonverbal communication. Some social media sites such as Snapchat allow access to enhanced technological interface that allow for increased user participation rather than social media platforms such as Twitter that limits user interactions to 140 characters.

\section{Deception cues}

Briscoe, Appling \& Hayes (2014) analyzed deception cues in a study to determine deception cues communicated on social media used three features: sentence structure, linguistic cues and data set analysis relative to individual presentations in experimental studies. The work was able to analyze the distinctions between deceptive and non-deceptive elements within the sample structure reviewed based on sentence length, structure complexity, sentiments and emoticon usage among others.

Findings established that several cues to deception exist in social media communication and that a person's personality or personality traits communicated may be a predictive tool in identifying certain deceptive strategies deployed. The table below shows the presentation of findings and tools used in analysis of the study. 


\section{International Academic Conference on Research in SOCIAL SCIENCES}

\begin{tabular}{|c|c|c|}
\hline Cue & Description & Cue Levels \\
\hline \multirow{3}{*}{ Sentence Length } & \multirow{3}{*}{$\begin{array}{l}\text { The average number of non-punctuation } \\
\text { tokens used in each sentence per conversation } \\
\text { turn. }\end{array}$} & High -8 Words \\
\hline & & Neutral -6 Words \\
\hline & & Low -4 Words \\
\hline \multirow{3}{*}{$\begin{array}{l}\text { Sentence } \\
\text { Complexity }\end{array}$} & \multirow{3}{*}{$\begin{array}{l}\text { The complexity of the conversation turn } \\
\text { measured as the average Flesch-Kincaid } \\
\text { reading score. }\end{array}$} & $\begin{array}{c}\text { High - 5 Prepositions / Complex } \\
\text { Phrases }\end{array}$ \\
\hline & & $\begin{array}{c}\text { Medium - } 3 \text { Prepositions / Complex } \\
\text { Phrases }\end{array}$ \\
\hline & & Low - 1 Preposition / Complex Phrase \\
\hline \multirow{3}{*}{ Sentiment } & \multirow{3}{*}{$\begin{array}{l}\text { The average sentiment as measured by the } \\
\text { AFINN valence dictionary }[21] \text { on a range of } \\
{[-5,+5] \text { across all sentences in a conversation }} \\
\text { turn. }\end{array}$} & $\begin{array}{c}\text { High - } 3 \text { Positive Sentiment-laden } \\
\text { Words }\end{array}$ \\
\hline & & Neutral - 0 Sentiment-laden Words \\
\hline & & $\begin{array}{c}\text { Low - } 3 \text { Negative Sentiment-laden } \\
\text { words }\end{array}$ \\
\hline \multirow{3}{*}{ Txt-Informality* } & \multirow{3}{*}{$\begin{array}{l}\text { The ratio of the number of suggested spelling } \\
\text { corrections to the total number of correctly } \\
\text { spelled words in a conversational turn. }\end{array}$} & High -6 informal tokens \\
\hline & & Neutral - 4 informal tokens \\
\hline & & Low - 2 informal tokens \\
\hline \multirow{2}{*}{ Emoticon Usage* } & \multirow{2}{*}{$\begin{array}{l}\text { The magnitude of emotions used in a } \\
\text { conversational turn. }\end{array}$} & High-emoticons present \\
\hline & & Low - No emoticons present \\
\hline
\end{tabular}

Table 1: A description of the linguistic cues analyzed as derived from (Briscoe, Appling, \& Hayes, 2014)

Deception may also be recognized as a deliberate message conveyed which is not a reflection of the subject- sender's true meaning. This may be in an effort to deflect scrutiny into a person's activities. However, it can be noted that subject- sender may also deploy a means known as posed deception to mask their true intentions. Posed deception can be understood as a situation in which social rules or etiquettes prevent the sender from openly acknowledging his/her true meaning but allow the alternative of communicating his/her meaning through nonverbal communicative cues (Zuckerman M. L., 1978).

Voice inflection or tonal quality and facial expressions can also be considered as cues to deduce deception (Fay \& Middleton, 1941; Harrison et al., 1978; Maier \& Thurber, 1968). However many studies have tried to establish a relationship between smiling and deception as well as other forms of facial expressions. The non-verbal communication of smiling while responding to questions could either be a function of sincerity or honesty or practiced in a bid to relax the facial muscles in efforts to convince with facial expressions (McClintock \& Hunt, 1975). Deceivers are therefore 
more likely to smile in trying to convince receivers of their honesty. This assertionateg ates the idea that smiling can be a tell-tale sign of truth telling and may not be entirely connected withe eqp International Academic Conference on Research in

\section{SOCIAL SCIENCES}

8 - 10 November, 2019

OXFORD, UNITED KINGDOM

Interestingly, with pitch and tone of voice, a clearer distinction can be made to determine if honesty is achieved or if truth is being told. According to Ekman et al. (1976), when a person is lying, vocal pitch tends to be higher and through this means, the receiver can deduce the genuineness of utterances (Streeter, Krauss, Geller, Olson, \& Apple, 1977).

Individuals who are adept at manipulating their facial features for instance actors and theatre performers are usually also able to manipulate their vocal timbres. People who make impressions of other people are also included in this category as they are also likely to have a knack for manipulating their facial features (Cunningham, 1977; Levitt, 1964; Zaidel \& Mehrabian, 1969; Zuckerman, Lipets, Koivumaki, \& Rosenthal, 1975).

Detectability can be achieved through two major channels; firstly by determining the attributes associated with expressions of honesty or deception as well as determining the relationship between channels and modes of communication (facial and vocal).

Assertions of dominance and pleasantness which are considered tools of honesty/deception detection, are attributes that are better detected through vocal channels rather than facial ones This does not diminish however, the receivers bias as there is also the chance that the receiver may have a desire to interpret the expressions as honest and may be oblivious to deception cues emitted by the subject-sender. The judges of deception cues play a significant role as well in detecting accurately, the deceiver's messages and deduce deception patterns for detectability (Buck, 1975; Buck, Savin, Miller, \& Caul, 1972; Buck et al., 1974).

\section{Social Media}

The advent of Social media since the 90's and its progression over the years has changed the communication space and model over the years. Many technology gurus and authorities could not have predicted or completely envisioned the speed, the rate and capacity of development of the Social media and its trends available in today's world. Many businesses, industries and individuals have fully embraced this trend and are using these platforms to transform their businesses and reach their audience faster and more effectively.

Social media platforms like Facebook, Twitter and Instagram user participation accounts for over $82 \%$ of the World's total online content consumption (Dhanyasree, Krishnan \& Amma, 2015). The major advantage to Social media includes the elimination of gatekeepers and allows for direct engagement with users and audiences. However, this also presents another issue which is that of 
information verification and deception protection. The major advantage of the media landscape lies in the fact that barriers to account registration and user access are

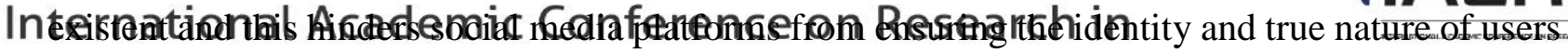
SOCIAL SCIENCES

on the platform. False or fake information can therefore be generated and propagated with minimal means of verifying the information disseminated. This is what is termed as deception. This is understood to be a deliberate process of transmitting false information using social media as a vehicle of propagation.

Admittedly, deceit and lies are prevalent in day to day operations and relationships with people (DePaulo, Ansfield \& Bell., 1996) however, the motivations for these deceptive tendencies may not be altogether negative. Deception may be employed to protect other people's feelings and emotions, maintain the stability of the status quo or offer others a feeling of security or even guard against the perpetration of certain insidious activities.

The important point to note is that this deception tends to offer a false sense of security which over time, eventually leads to its uncovering and results in a loss of trust and credibility in relationships (Owen, Fincham \& Manthos, 2013). This distrust may irreparably damage these relationships to the extent that a complete loss of faith may be present for many years or never recovered entirely (Steinel, \& De Dreu, 2004).

According to Zuckerman, DePaulo, and Rosenthal (1981) what is termed as "the communication of deception" embodies the coexistence of 'Lying and lie detection'. Deception is considered as the perpetration of an act with the intent to motivate another party or person to believe of buy into an idea or concept that the deceiver considers to be untrue.

The deceiver is understood to be the individual or party that seeks to communicate false information through Social or Online media as is the context of our study. Several Social media platforms exist and are available to content consumers, the most popular of these include: Facebook, Twitter, Instagram, LinkedIn. This category also includes blogs, content communities, gaming sites and social networking sites among others (Kaplan and Haenlein). 


\section{International Academic Conference on Research in SOCIAL SCIENCES}

\begin{tabular}{|c|c|c|c|c|c|}
\hline & \multicolumn{4}{|c|}{ Social presence / Media richness } \\
\hline & & Low & & & High \\
\hline \multirow{2}{*}{$\begin{array}{l}\text { Self-presentation } \\
\text { / Self-disclosure }\end{array}$} & Low & $\begin{array}{c}\text { Collaborative } \\
\text { projects }\end{array}$ & Social news sites & $\begin{array}{c}\text { Content } \\
\text { communities }\end{array}$ & $\begin{array}{c}\text { Virtual game } \\
\text { worlds }\end{array}$ \\
\hline & High & Blogs & Microblogging & $\begin{array}{c}\text { Social networking } \\
\text { sites }\end{array}$ & $\begin{array}{c}\text { Virtual social } \\
\text { worlds }\end{array}$ \\
\hline
\end{tabular}

Table 2: Social media classifications culled from Tsikerdis \& Zeadally (2014)

According to Social media classifications illustrated in Tsikerdekis \& Zeadally (2014) as shown in Table 2 above, the users with the higher deception perpetration opportunities are classified in the second row of Table 1 while the first row illustrates the users with the lower freedom of opportunity for deception. This means that the content communities, social news sites, etc to a certain extent force users to adapt to certain roles and disclose their identities partially while the second row allows more latitude for deception.

With regard to media richness and social presence, the variations in virtual gaming and virtual social worlds could affect how deception is achieved and implemented. The asynchronous nature of SM text-based communication allows deceivers to easily manipulate content dispersed in order to perpetrate deception. Several factors are considered by the deceiver when trying to achieve online deception and this can affect how easy or difficult the process progresses. The factors include goals or objective of deception, the expectation of deceiver and receiver, familiarity level or relationship with target as well as the level of suspicion exhibited by the target or receiver.

Goals are motivations that require a person to take certain measure in order to achieve them. They can influence the type or choice of deceptive act (Buller \& Burgoon 1994). This means that the deceiver has to consider the end goal of deception. How profitable it is or the advantage to be gained and this influences how elaborate the scheme is designed and implemented to facilitate the goal or objective in mind. 
The expectation of the sender will influence just how far the deceiver is willing tof fis to achieve success and if it is indeed worth the trouble of perpetrating an elaborate scheme to achidy

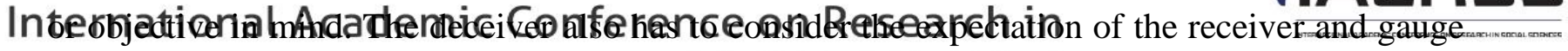

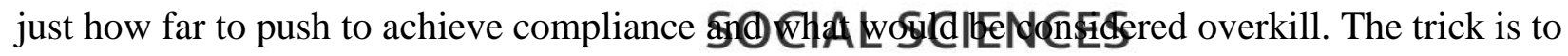
8 - determine what exactly the receiver wants tQ see or hear that, can be provided or generated to

convince him or her to participate in the process and help to achieve the deceivers own expectations. Without giving away too much or revealing the deceivers self too much that can blow back on or affect the deceivers own security or the end result in general.

The relationship with the target can also play a role in the deception process on social media. The target develops a relationship with the target over time by engaging in certain conversations and winning the trust of the target. After which, the level of relationship will determine when and how to perpetrate the deception to meet the deceivers goal or intentions. This is usually a deliberate and well cultivated affair that results in the deceiver's understanding of the weaknesses and strength of the target as well as determining the best possible state to attain in order to achieve optimum results (Zahavi, 1993).

\section{Theoretical background}

Several theories are significant in understanding deception and its impact in communication both verbally and nonverbally. One of the theories of interest is the theory of leakage cues propounded by Ekman Friesens in 1969. This theory holds that in communication, the deceiver or subject sender is prone to emitting cues unwittingly. In the case of communicating the cues unwittingly, the deceiver is unaware that he/she is giving off certain signs or signals that can help the receiver to judge their sincerity/deception levels. The deceiver therefore is not aware that he/she is being observed or is he/she aware that these signals are released entirely (Collett 2003; Ekman et al. 1991; Navarro and Karlins 2008 Hartwig \& Bond 2011).

The expectancy violations theory (EVT) by Judee K. Burgoon in the late 1970s is also interesting in the sense that it explains that an individual's behavior can violate the expectations of another person. It elaborates on the fact that one individual's intentions can be superimposed on another person such that the other person begins to fulfill the deceiver's expectations. It is therefore a communicative theory based on signals emitted by one and perceived by another while resulting in favorable outcomes for the other party. In turn, while observing interactions, the focus could be geared towards comparing an expected or anticipated reaction with a received one in order to detect deceptive actions or tendencies. EVT can be used to better understand deception detection through digital analysis of body movements. 
The major theory of focus in this work is the Interpersonal Deception Theory (IDF) ynam because it encompasses the areas of interest in the communication of deception especilly $\sqrt{1 t h} \Omega 55$

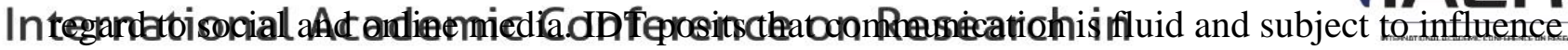
by personal intentions, expectations and megn்gs|gf inteperspnet ingeraction. The direct and indirect communication of the sender may be influenced by the direct or indirect communication 8 - 10 November 2019 compases formal and informal communication as well as verbal and

nonverbal communication) and individuals manage deception at either a conscious or a subconscious level. Intentional deception requires a deliberate cognitive effort to implement as opposed to honesty in communication. This is also known as 'strategic decision' of deception and regardless of whether it is an outright lie, a white lie or a concealment of facts or portions of information, IDT investigates the senders meaning while communicating and the receivers perception or resultant behavior upon receipt of communication conveyed by the sender in deceptive exchanges

IDT was propounded by two communication experts, David B. Buller and Judee K. Burgoon. Before the formulation of this theory, deception had not been extensively studied as a communication concept but was rather considered a principle for evaluating lies and how they could be detected from a unidirectional perspective. The IDT was however an effort to explain how the deception process is a product of communicative cues being passed from one individual to another with feedback mechanisms that determine the progression of deception towards achieving expectations from the parties involved

\section{Receiver's role}

Prior to the IDT, the general belief was that deception may be detected by the casual observer. However, the IDT posits that this is not the case. A deceiver is adept at managing apparent cues to ensure that the true intentions are masked from the perception of the receiver. However, if the receiver is socially aware and awake to the wiles of the deceiver, then he/she can be better equipped to detect deceit.

Our argument in this work centers on the hypothesis that nonverbal communication could be a better option in detecting deception in communication and the IDT supports this assertion. Hand movements, eye movements and body movement analysis have been used in Tsikerdekis \& Zeadally (2014) to provide a 98-100\% accuracy of deception detection on social media and online platforms for non-verbal communication while the verbal communication patterns of text and audio (voice stress and speech patterns) constitute about 56-92\% accuracy in communication detection. 
The Four Factor Theory is a complementary theory adopted to anchor this work DePaulo, \& Rosenthal, 1981). It states that four primary markers are evident in liars dr de eiv er 5

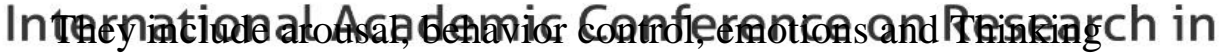

\section{SOCIAL SCIENCES}

Arousal: The action of lying has been understood to cause anxiety and physical reactions such as

8 - 10 Nidgeting, blinking, nervous ticks, elevated vocal pitches and pupil dilation that may not be

apparent to the perpetrator. Anxiety evoked in the individual reflects the fear within the subject and may therefore be evident in the individual's reaction.

Behavior control: This refers to leakage cues that slip through the cracks despite the deceivers best efforts to conceal the true nature of his intentions. Fidgeting and unnecessary smiling as well as nervous ticks may be classified under this category. The people within this category make efforts to control their responses and the effort made to hide their intentions become the very actions that give them away.

Emotion: Expressions of guilt or fear and micro-movement or changes in facial features reflect emotional responses and hidden emotion. Small changes to our thought patterns can also affect our responses and may be tell-tale signs. Even relief at getting away with lying can be a sign of deception

Thinking: Lies require a complex cognitive exertion. This means that to deceive others, an elaborate thought process is required to maintain coherence in story fabricated. This in turn affects our speech construction. Deceivers who fall under this category tend to be vague and evasive.

\section{Conclusion}

In today's social media space, billions of users all over the world have become susceptible to deceptive preys on a network seemingly without a lot of control. Therefore, the onus lies on social network providers to increase security measures to guard against deceptive users. After establishing the issues relating to deception in previous chapters, it is pertinent to note that measures can be taken to identify and guard against deceptive tendencies on social media networks or platforms. Social media sites can generate bots to allow users to respond to certain questions that can indicate the tendencies of the users and use their media consumption patterns to ascertain their penchant for deceptive tendencies. Identities of users can be verified as users with sudden social media histories can be monitored for flagging as potential deceivers. An upgrade to the currently existing standardization process and profiling may also be required to monitor user history and guard against potential threats. 
Although the distance between deceiver and receiver may seem vast, social media spaca hass served

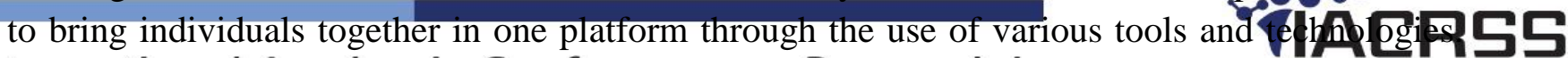

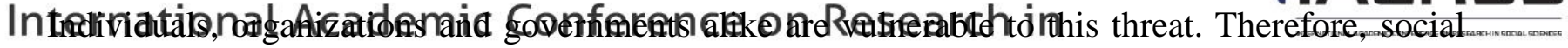

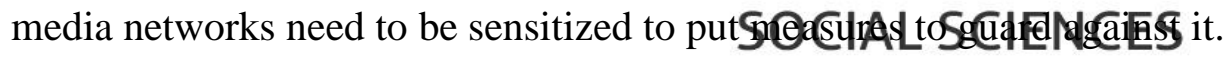

\section{References}

Argyle, M. (1996). Bodily Communication. London: Routledge.

Axtell, R. (1998). Gestures. New York: John Wiley.

Boyle, R. J., \& Ruppel, C. P. (2005). The Impact of Media Richness, Suspicion, and Perceived Truth Bias on Deception Detection. 38th Annual Hawaii International Conference on System Sciences, (pp. 20a-20a).

Briscoe, Appling, \& Hayes. (2014). Cues to Deception in Social Media. 2014 47th Hawaii International Conference on System Science (pp. 1435-1443). Georgia: Georgia Tech Institute.

Buck, R. (1975). Nonverbal communication of affect in children. Journal of Personality and Social Psychology, 644-653.

Buck, R., Miller, R. E., \& F., G. W. (1974). Sex, personality, and physiological variables in the communication of affect via facial expression. Journal of Personality and Social Psychology, 587-596.

Buck, R., Savin, V. J., Miller, R. E., \& Caul, W. F. (1972). Communication of affect through facial expressions in humans. . Journal of Personality and Social Psychology, 362371.

Buller, D., \& Burgoon, J. (1996). Interpersonal Deception Theory. Communication Theory, 203-242.

Burgoon, Buller, White, Afifi, \& Buslig. (n.d.). Personality and Social Psychology Bulletin. 669-686., 669-686.

Burgoon, J., \& Qin, T. (2006). The Dynamic Nature of Deceptive Verbal Communication. Journal of Language and Social Psychology, 76-96.

Capella \& Greene, 1. (1982). A discrepancy-arousal explanation of mutual influence in expressive behavior for adult-adult and infant-adult interaction. Communications Monographs, 89-114.

Collett, P. (2003). The book of tells. New York: Bantam.

Cunningham, M. R. (1977). Personality and the structure of the nonverbal communication of emotion. Journal of Personality, 564-584. 
DePaulo, B., Ansfield, M., \& Bell, K. (1996). Theories About Deception and Patrarkg for Studying It: A Critical Appraisal of Buller and Burgoon's Interpersonal Dectpfip RS马

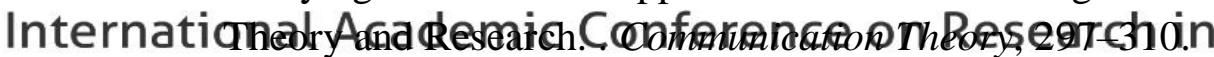

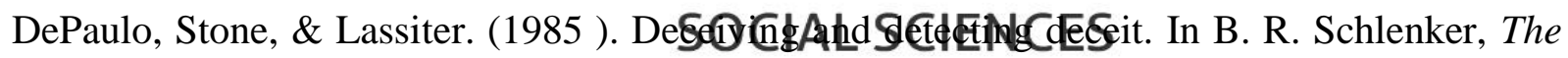

8 - 10 Novemelfand sogial life (pp. 323-370) Xfew, York:McGraw Hill.

Dhanyasree, P., Krishnan, S., \& Ambikadevi, A. T. (2015). Deception Detection in Social

Media through Combined Verbal and Non-Verbal Behavior. International Journal of Advanced Research in Computer Science and Software Engineering, 445-448.

Donath, J. S. (1999). Identity and deception in the virtual community. In M. A. Smith, \& P. Kollock, in Communities in Cyberspace,. Routledge.

Ekman, \& O’Sullivan. (1991). Who can catch a liar. American Psychologist, 913-920.

Ekman, P., \& Friesen, W. V. (1969). Nonverbal leakage and clues to deception. Psychiatry: Interpersonal and Biological Processes, 88-106.

Ekman, P., Friesen, W. V., \& Scherer, K. R. (1976). Body movement and voice pitch in deceptive interaction. Semiotica, 23-27.

Fay, \& Middleton. (1941). The ability to judge truth-telling, or lying, from the voice as address system. The Journal of General Psychology, 24.

Fichten, Tagalakis, Judd, Wright, \& Amsel. (2001). verbal and nonverbal communication cues in daily conversations and dating. Journal of social psychology, 751-769.

Harrison, A. A., Hwalek, M., F., R. D., \& Fritz, J. G. (1978). Cues to deception in an interview situation. Social Psychology, 156-161.

Hartwig, M., \& Bond, C. J. (2011). (2011) Why do lie-catchers fail? A lens model metaanalysis of human lie judgements. Psychological Bulletin, 643-659.

J, N., \& M, K. (2008). What every BODY is saying. New York: Harper Collins.

Kaplan, AM, \& Haenlein, M. (2010). Users of the world, unite! The challenges and opportunities of Social Media. Bus Horizon, 59-68.

Kleck, R., \& Nuessle, W. (1968). Congruence between the indicative and communicative functions of eye contact. British Journal of Social and Clinical Psychology, 107-114.

Levitt, A. E. (1964). The relationship between abilities to express emotional meanings vocally and facially. In J. R. Davitz, The communication of emotional meaning. New York: McGraw-Hill.

Maier, N. R., \& Thurber, J. A. (1968). Accuracy ofjudgment of deception when an interview is watched, heard, and read. Personnel Psychology, 23-30.

McClintock, C. C., \& Hunt, R. G. (1975). Nonverbal indicators of affect and deception in an interview setting. Journal of Applied Social Psychology, 54-67. 
McFall, R. (1982). A review and reformulation of the concept of social Assessment, 1-33.

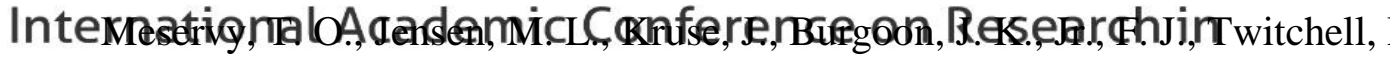

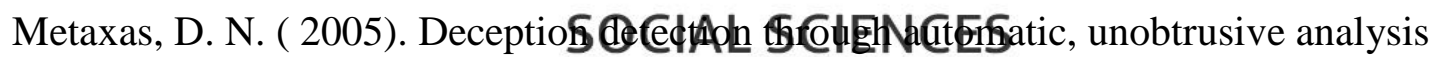

8 - 10 Nove of nonverbagl behavior. IEEE Intelligent, Systems, 36 iN $430 \mathrm{~m}$

Owen, J., Fincham, F., \& Manthos, D. (2013). Friendship After a Friends with Benefits Relationship: Deception, Psychological Functioning, and Social Connectedness. . Archives of Sexual Behavior, 1443-1449.

Park, H. S., Levine, T., McCornack, S., Morrison, K., \& Ferrara, M. ( 2002). How people really detect lies. Communication Monographs, 144-157.

Pérez-Sabater, C. (2012). The Linguistics of Social Networking: A Study of Writing Conventions on Facebook. Linguistik online, 82.

Riggio, R. E., \& Friedman, H. S. (1986). Impression formation: The role of expressive behavior. Journal of Personality and Social Psychology, 421.

Sherman, X. S. (2013). Security and privacy in mobile social network. IEEE Network, 2-3.

Steinel, W., \& De Dreu, K. W. (2004). Social motives and strategic misrepresentation in social decision making. . Journal of Personality and Social Psychology, 419 - 434.

Stiff, J. (1996). Theoretical Approaches to the Study of Deceptive Communication: Comments on Interpersonal Deception Theory. Communication Theory, 289-296.

Stiff, J. B., \& Miller, G. R. (1986). "Come to think of it...' ': Interrogative probes, deceptive communication and deception detection. Human Communication Research, 339-357.

Streeter, L. A., Krauss, R. M., Geller, V., Olson, C., \& Apple, W. ( 1977). Pitch changes during attempted deception. Journal of Personality and Social Psychology, 345-350.

Tsikerdekis, M., \& Zeadally, S. (2014). Online deception in social media. Commun. ACM.

Tsikerdekis, M., \& Zeadally, S. (2014). Multiple Account Identity Deception Detection in Social Media Using Nonverbal Behavior. Kentucky: Information Science Faculty Publications.

Wainwright, G. (2003). Body Language. London.: Hodder.

Williams, D. (1997). Communication Skills in Practice: A Practical Guide for Health Professionals. London: Jessica Kingsley.

Zahavi, A. (1993). The Fallacy of Conventional Signalling. Philosophical transactions of the Royal Society of London( Series B, Biological sciences), 227-230.

Zaidel, S. F., \& Mehrabian, A. ( 1969). The ability to communicate and infer positive and negative attitudes facially and vocally. Journal of Experimental Research in Personality, 233-241. 
Zuckerman, M. L. (1978). Posed and spontaneous communication of emotiouforia-acial and vocal cues. Journal of Personality.

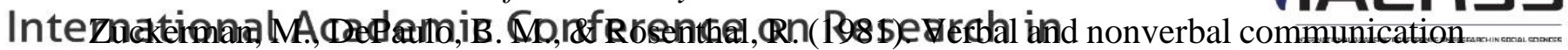

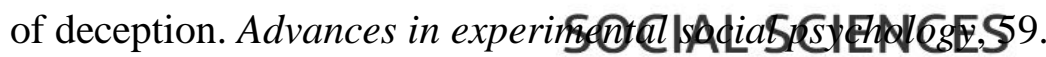

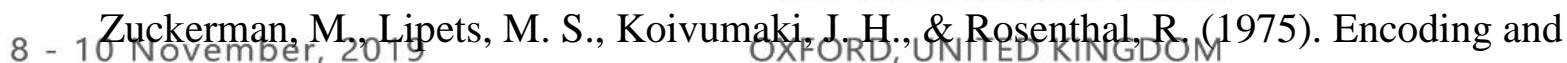
decoding nonverbal cues of emotion. Journal of Personality and Social Psychology, 1068-1076. 